\title{
The Orbiting Carbon Observatory-2 early science investigations of regional carbon dioxide fluxes
}

\author{
Authors: A. Eldering ${ }^{1}$, P.O. Wennberg ${ }^{2}$, D. Crisp ${ }^{1}$, D. Schimel ${ }^{1}$, M.R. Gunson ${ }^{1}$, A. \\ Chatterjee $^{3,4}$, J. Liu ${ }^{1}$, F. M. Schwandner ${ }^{1}$, Y. Sun ${ }^{1}$, C.W. O’Dell ${ }^{5}$, C. Frankenberg ${ }^{2}$, T. Taylor ${ }^{5}$, B. \\ Fisher $^{1}$, G.B. Osterman ${ }^{1}$, D. Wunch ${ }^{6}$, J. Hakkarainen ${ }^{7}$, J. Tamminen ${ }^{7}$, B. Weir ${ }^{3,4}$
}

\author{
Affiliations: \\ ${ }^{1}$ Jet Propulsion Laboratory, California Institute of Technology, Pasadena, CA. \\ ${ }^{2}$ Divisions of Geology and Planetary Sciences and Engineering and Applied Science, California \\ Institute of Technology, Pasadena, CA. \\ ${ }^{3}$ Universities Space Research Association, Columbia, MD. \\ ${ }^{4}$ NASA Global Modeling and Assimilation Office, Greenbelt, MD. \\ ${ }^{5}$ Cooperative Institute for Research in the Atmosphere, Colorado State University, Fort Collins, \\ CO. \\ ${ }^{6}$ currently University of Toronto, Department of Physics, prior to December 2015 was Division \\ of Geology and Planetary Sciences, California Institute of Technology, Pasadena, CA. \\ ${ }^{7}$ Finnish Meteorological Institute, Earth Observation, Helsinki, Finland.
}

*Correspondence to: Annmarie.Eldering@jpl.nasa.gov

\begin{abstract}
:
NASA's Orbiting Carbon Observatory-2 (OCO-2) mission was motivated by the need to diagnose how the increasing concentration of atmospheric carbon dioxide $(\mathrm{CO} 2)$ is altering the productivity of the biosphere and the uptake of CO2 by the oceans. Launched on July 2, 2014, OCO-2 provides retrievals of the total column carbon dioxide $\left(\mathrm{X}_{\mathrm{CO} 2}\right)$ as well as the fluorescence from chlorophyll in terrestrial plants. The seasonal pattern of uptake by the terrestrial biosphere is recorded in fluorescence and the drawdown of $\mathrm{X}_{\mathrm{CO} 2}$ during summer. Launched just prior to one of the most intense El Niños of the past century, OCO-2 measurements of $\mathrm{X}_{\mathrm{CO} 2}$ and fluorescence record the impact of the large change in ocean temperature and rainfall on uptake and release of $\mathrm{CO}_{2}$ by the oceans and biosphere.
\end{abstract}

One Sentence Summary: Variability in atmospheric carbon dioxide $\left(\mathrm{CO}_{2}\right)$ and the pattern of plant chlorophyll fluorescence from the Orbiting Carbon Observatory-2 measurements reflect the changing regional sources and sinks of $\mathrm{CO}_{2}$ across the globe.

\section{Main Text:}

Key Questions in the Carbon Cycle 
Large fluxes of carbon dioxide $\left(\mathrm{CO}_{2}\right)$ between the atmosphere, land biosphere, and oceans (1) occur within Earth's carbon cycle. The exchange varies seasonally, with net carbon uptake into the terrestrial biosphere during the growing season, especially in the Northern Hemisphere. In the fall and winter, photosynthesis declines in the mid and high latitudes, and plant respiration exceeds photosynthesis, returning $\mathrm{CO}_{2}$ to the atmosphere. Continuing emissions of $\mathrm{CO}_{2}$ from fossil fuels adds carbon to the atmosphere, mostly in the Northern Hemisphere (2). The uptake of $\mathrm{CO}_{2}$ from the atmosphere into the land and oceans constitutes between $20 \%$ and $80 \%$ of $\mathrm{CO}_{2}$ emissions from fossil fuel and land use change $(3,5)$, and is $\sim 50 \%$ on average. The balancethat is, the fraction of anthropogenic carbon release not reabsorbed by the Earth System-is referred to as the 'airborne fraction'. It is manifest in the rising burden of atmospheric $\mathrm{CO}_{2}$, whose concentration is increasing $0.50-0.75 \%$ each year $(2-3 \mathrm{ppm} / \mathrm{yr}$ increase in the atmospheric mole fraction) (4).

Subtle geographic and temporal variations in atmospheric concentrations of $\mathrm{CO}_{2}$, of fractions of a ppm to several ppm of the ambient $\sim 400$ ppm background, reflect the underlying uptake and release of carbon. These variations provide clues to the underlying mechanisms that drive differences in the airborne fraction. Measurements of the increasing inventory of carbon in seawater indicate that almost a quarter of the $\mathrm{CO}_{2}$ emitted by human activities is being absorbed by the ocean $(6)$, where it contributes to ocean acidification. Mass balance demands that another quarter of the $\mathrm{CO}_{2}$ emitted by human activities must be absorbed by processes on land. The identity and location of these sinks are less well understood. Some studies have attributed this absorption to tropical (7), or Eurasian temperate (8) forests, while others indicate that these areas are just as likely to be net sources as net sinks of $\mathrm{CO}_{2}(9)$. The efficiency of these natural land and ocean sinks also appears to vary dramatically from year to year (3). Because the identity, location, and processes controlling these natural sinks are not well constrained, it is not clear how they will respond in the future (7). Understanding these mechanisms and their dependence on climate and atmospheric $\mathrm{CO}_{2}$ levels is central to understanding how the carbon cycle may amplify or mitigate future climate change $(3,7,10-13)$.

\section{Measuring $\mathrm{CO}_{2}$ from Space with OCO-2}

The international network of ground-based in situ greenhouse gas measurement stations provides a long term and precise $(\sim 0.07 \mathrm{ppm})$ record of the atmospheric $\mathrm{CO}_{2}$ concentration at approximately 147 locations across the globe $(14,15)$. Few measurements are obtained in tropical regions, in urban settings, or in Asia. The NASA satellite, the Orbiting Carbon Observatory-2 (OCO-2), which launched from Vandenberg Air Force Base in California on July $2^{\text {nd }}, 2014$, is designed to collect global measurements with sufficient precision, coverage, and resolution to aid in resolving sources and sinks on regional scales. After completing a series of spacecraft check-out activities and orbit-raising maneuvers, on 3 August 2014, it joined the front of the Afternoon Constellation (A-Train) (16), which consists of six satellites orbiting at an altitude of $705 \mathrm{~km}$. In this 98.8 minute orbit, OCO-2 samples at a local time of about 1:30pm, and it has a set of 233 orbit paths that repeat in 16 day cycles. The OCO-2 sampling strategy repeats in 32 day cycles. Since 6 September 2014, the OCO-2 instrument has been routinely returning almost 1 million soundings each day over the sunlit hemisphere. This measurement concept was developed in the late 1990's, but this type of data has only been collected since 2014. The OCO-2 mission is a replacement for the original OCO instrument and spacecraft that 
were lost in a failed launch in February 2009; only small modifications to replace obsolete parts and to adapt to a different launch vehicle were required.

The OCO-2 spectrometers collect 8 spatially-resolved radiance spectra of reflected sunlight in three narrow wavelength bands three times a second, with resolving power $(\Delta \lambda / \lambda)$ of $\sim 17000$ (Fig. 1) (17-19). The oxygen A-band (centered at $\sim 765 \mathrm{~nm}$ ) provides a sensitive measure of the atmospheric path length and is thus an accurate indicator of clouds and surface elevation. The radiance at two distinct carbon dioxide absorption bands (1.61 and 2.06 microns) provides sensitivity to $\mathrm{CO}_{2}$. The column-averaged atmospheric $\mathrm{CO}_{2}$ dry air mole fraction $\left(\mathrm{X}_{\mathrm{CO} 2}\right)$ or the total column of carbon dioxide normalized by the column of dry air is derived from these spectra using a physics-based retrieval method (20-22). The sensitivity of the measurement is fairly uniform throughout the troposphere and lower stratosphere, and varies with solar geometry and surface (23). Details of the instrument calibration and observatory operation are reported in Crisp et al.(19), and the data processing strategy is described by Eldering et al. (24).

A set of eight measurements are made along a narrow ground track as the spacecraft travels about $2.25 \mathrm{~km}$ along its orbit track, providing spatial resolution of $<3 \mathrm{~km}^{2}$ per sounding. $\mathrm{X}_{\mathrm{CO} 2}$ is retrieved only when there is sufficient light (solar zenith angles less than 85 degrees) and when there are no optically-thick clouds (25). OCO-2 returns roughly 2 million $\mathrm{X}_{\mathrm{CO} 2}$ estimates each month that pass quality screening (Fig. 2), for a yield of about $6 \%$ of the total soundings.

Systematic biases in the OCO-2 $\mathrm{X}_{\mathrm{CO} 2}$ estimates must be minimized to accurately resolve the small spatial and temporal variations in this quantity. The bias correction, designed to address known systematic errors, takes advantage of the high density of soundings gathered over regions with minimal variability in $\mathrm{X}_{\mathrm{CO} 2}$ (such as contiguous data collected in small areas and over the Southern Hemisphere oceans) $(26,27)$. To relate the OCO-2 $\mathrm{X}_{\mathrm{CO} 2}$ estimates to the standard $\mathrm{CO}_{2}$ scale set by the international $\mathrm{CO}_{2}$ in situ network, we use the transfer standard provided by a specially-designed ground-based network of atmospheric observatories that comprise the Total Carbon Column Observing Network (TCCON) (28). Extensive comparisons have been made between OCO-2 satellite measurements coincident with the TCCON measurements $(29,30)$. After correcting biases, the OCO- $2 \mathrm{X}_{\mathrm{CO} 2}$ retrievals have median differences [for collections of $>$ 100 soundings] of less than $0.5 \mathrm{ppm}$ and root-mean-square differences that are typically below $1.5 \mathrm{ppm}$ (30). Simulation studies conducted before the launch of OCO estimated that large climate anomalies, like the 2003 European summer drought, which created a carbon anomaly of $0.5 \mathrm{Gt} \mathrm{C} \mathrm{(31),} \mathrm{would} \mathrm{be} \mathrm{detected} \mathrm{by} \mathrm{OCO,} \mathrm{whereas} \mathrm{scientific} \mathrm{questions} \mathrm{about} \mathrm{smaller} \mathrm{changes} \mathrm{(of}$ order $0.01 \mathrm{Gt} \mathrm{C}$ ) would not be addressed by OCO (32). The systematic biases from OCO-2 are consistent with the pre-launch design studies. As discussed in Chatterjee et al (33), concentration changes of 0.5 ppm regionally can be detected with the OCO-2 measurements.

The interpretation of OCO-2 measurements is enhanced by measurements from the other Earth observing satellites. The availability of measurements of trace gases such as nitrogen dioxide $\left(\mathrm{NO}_{2}\right)$ from the Ozone Monitoring Instrument (OMI), carbon monoxide $(\mathrm{CO})$ from the Measurement of Pollution in the Troposphere experiment (MOPITT), and many products from the Moderate Resolution Imaging Spectroradiometer (MODIS), have been used to disentangle the influence of complex and variable processes that contribute to the global carbon cycle (3437).

\section{Measuring Plant Fluorescence from Space with OCO-2}


Measurements of solar-induced chlorophyll fluorescence (SIF) from satellites offer new insight into terrestrial gross primary productivity (GPP), the gross uptake of $\mathrm{CO}_{2}$ through photosynthesis (38). The SIF signal, a small amount of light emitted during photosynthesis, is detected in remote sensing measurements of radiance within solar Fraunhofer lines. Retrieval methods were developed in recent years with the Japanese Greenhouse gases Observing SATellite (GOSAT) Fourier Transform Spectrometer (TANSO-FTS), Global Ozone Monitoring Experiment-2 (GOME-2) onboard MetOp-A, and OCO-2 measurements, and its potential for quantifying gross primary productivity (GPP) is being assessed (38-42). Although the SIF signal is quite small enhancements are typically less than $2 \%$ of the reflected sunlight (43) - the high signal-to-noise spectra from OCO-2 enable precise SIF measurements at high spatial resolution (37). Typically, the random component of the retrieval error varies between 0.3 and $0.5 \mathrm{Wm}^{-2} \mu \mathrm{m}^{-1} \mathrm{sr}^{-1}(15-$ $25 \%$ of typical peak values of SIF) in the $757-n m$ fitting window (44), but the errors are substantially reduced by a factor $1 / \sqrt{ } \mathrm{n}$ if single retrievals (from individual soundings) are binned to gridded maps ( $\mathrm{n}$ is the number of soundings per gridcell) at certain temporal averaging domains. In a companion paper in this issue, Sun et al. (37) describes OCO-2 SIF characteristics in detail, and illustrates mechanistic connections between SIF and GPP. They show that when OCO-2 data are compared to gross primary productivity from flux tower measurements, well matched in spatial scale, they have correlation coefficients ranging from 0.89 to 0.99 with similar slopes for 3 different biomes. Earlier studies that used sparse datasets that had to be interpolated over time indicated biome specific linear relationships.

\section{Observing the Carbon Cycle from Space with OCO-2}

Maps of the $\mathrm{X}_{\mathrm{CO} 2}$ data collected over three 32-day periods illustrate the most robust features of the carbon cycle (Fig. 2). The March/April 2015 distribution is characterized by enhanced $\mathrm{X}_{\mathrm{CO} 2}$ in the northern hemisphere. During winter, uptake by plants is minimal while the breakdown or decay of plant material continues. As a result of this, together with the continual emissions from fossil fuel burning (e.g. elevated $\mathrm{X}_{\mathrm{CO} 2}$ over China, Europe, and Southeast US), $\mathrm{X}_{\mathrm{CO} 2}$ reaches a seasonal maximum in the northern hemisphere during April just before temperatures increase enough to reawaken the biosphere from the low activity of winter. As illustrated in Fig. 3, active photosynthesis is manifest in the strong signal of plant fluorescence across the vegetated springtime Northern Hemisphere.

By June/July 2015, the distribution of $\mathrm{X}_{\mathrm{CO} 2}$ and fluorescence observed by OCO-2 has changed dramatically compared to March/April (Fig. 2 for $\mathrm{X}_{\mathrm{CO} 2}$ ). Although fossil fuel emissions continue, the uptake of $\mathrm{CO}_{2}$ by the terrestrial biosphere (e.g. Fig. 1 of (37)) has removed a large amount of $\mathrm{CO}_{2}$ from the atmosphere over much of the northern hemisphere; the latitudinal gradient of $\mathrm{X}_{\mathrm{CO} 2}$ has reversed. In 2015, OCO-2 observations indicate that the springtime drawdown began in Europe and propagated eastward across Asia and North America over the months of May and June. In some regions, $\mathrm{X}_{\mathrm{CO} 2}$ declined by $7 \mathrm{ppm}$ in only one month. Animation 1 illustrates the carbon dioxide from an atmospheric analysis, a product that merges OCO-2 observations with a high-resolution global model using a technique called data assimilation (45). The incorporation of OCO-2 observations corrects errors in the model's prediction of atmospheric $\mathrm{CO}_{2}$ concentrations while the model provides additional information about the vertical distribution of the gas and fills gaps in cloudy, data-sparse regions. Spanning March 2015 through the end of July 2015, the rapid reductions in carbon dioxide concentrations 
in the northern hemisphere during June are evident in this animation as are the complex pathways that transport $\mathrm{CO}_{2}$ through the atmosphere, across oceans and continents.

By March/April 2016, the distribution of $\mathrm{X}_{\mathrm{CO} 2}$ is similar to the year before, but with an increased concentration of approximately $3.5 \mathrm{ppm}$ globally. A substantial fraction of this increase reflects emissions from fossil fuel burning. Direct evidence for these emissions include the 1-3 ppm enhancements in $\mathrm{X}_{\mathrm{CO} 2}$ over the regions with intense industrial activity. For example, Schwandner et al. (46) observe a local, persistent enhancement of 4 to $6 \mathrm{ppm}$ in $\mathrm{X}_{\mathrm{CO} 2}$ between OCO-2 measurements across the Los Angeles basin and the measurements that extend to the desert region to the north. The basin provides an ideal setting for such analyses, with a large urban population and accompanying emissions, and mountains to the north of the city, which trap air in the basin and provide a clear demarcation from the background region to the north. This is illustrated in Fig. 4 and in Schwandner et al. (46). More broadly, the spatial enhancements of $\mathrm{X}_{\mathrm{CO} 2}$ due to the burning of fossil fuel across the northern hemisphere are illustrated in Fig. 5. Hakkarainen et al. (34) combined OCO-2 $\mathrm{X}_{\mathrm{CO} 2}$ measurements with space-based observations of $\mathrm{NO}_{2}$ from the OMI instrument, as well as the ODIAC $\mathrm{CO}_{2}$ emissions inventory (47). Using cluster analysis, they identified $\mathrm{X}_{\mathrm{CO} 2}$ enhancements clearly linked to fossil fuel combustion, which are shown in Fig. 5.

Another large signal seen in the OCO-2 data is the effect of seasonal biomass burning in Africa on the $\mathrm{X}_{\mathrm{CO} 2}$ concentrations (Fig. 6). $\mathrm{CO}_{2}$ accounts for more than $90 \%$ of annual global fire carbon emissions in current emission inventories (48), and fire emissions are typically enhanced during El Niño periods. These emissions have typically been estimated from models rather than direct observations. Uncertainties in the extent of the burned area, the biomass density within the burned area, and the fraction of biomass emitted as $\mathrm{CO}_{2}, \mathrm{CO}$ and other species compromise the accuracy of the estimates (49-51). Top-down constraints on pyrogenic $\mathrm{CO}_{2}$ could therefore provide a much-needed check on fire emissions estimates.

OCO-2 measurements were used to estimate the $\mathrm{CO}_{2}$ emissions from Indonesian fires in 2015 (35). Indonesia experienced an exceptional number of fires in 2015 due to El Niño-related drought and slash-and-burn agricultural practices. Emission databases such as the Global Fire Assimilation System (GFASv1.2) and the Global Fire Emission Database (GFEDv4s) estimated the $\mathrm{CO}_{2}$ emission to be approximately $1100 \mathrm{MtCO}_{2}$ between July and November 2015. Heymann et al. (35) analyzed OCO-2 $\mathrm{X}_{\mathrm{CO} 2}$ observations collected over Indonesia during this period using two different modeling approaches. They estimate pyrogenic $\mathrm{CO}_{2}$ emissions near $731 \pm 271$ $\mathrm{MtCO}_{2}$. This estimate is $37 \%$ and $31 \%$ lower than those in the GFASv1.2 and GFEDv4s emissions databases. Interestingly, the OCO-2 based estimates are consistent with pyrogenic $\mathrm{CO}_{2}$ emissions estimates based on $\mathrm{CO}$ measurements from the Measurement of Pollution in the Troposphere (MOPITT) instrument on the Terra platform, and fire radiative power estimates from Terra and Aqua MODIS (692 $\left.\pm 213 \mathrm{MtCO}_{2}\right)$ (52). Hakkarainen (34) also clearly sees the enhanced $\mathrm{X}_{\mathrm{CO} 2}$ from biomass burning in his anomaly analysis, although their results are aggregated over time, so the seasonality is not reported. The Northern Hemisphere African biomass emissions peak in January each year $(48,53)$, and have a duration of 4 to 5 months. Figure 6 illustrates the growth phase of that cycle for 2 years of OCO-2 measurements. 
Timeseries of the OCO- $2 \mathrm{X}_{\mathrm{CO} 2}$ estimates clearly show the seasonal cycles and the latitudinal differences in those seasonal cycles that are similar to the record collected by ground-based networks. Figure 7 shows weekly average $\mathrm{X}_{\mathrm{CO} 2}$ values for the South Pacific, the ocean around Hawaii, and a region over Europe/Asia. The South Pacific has a relatively flat seasonal cycle, as there are limited emissions and limited uptake by the terrestrial biosphere in this region. Around Hawaii, there is a stronger seasonal cycle, as it is influenced by the Northern Hemisphere springtime removal of $\mathrm{CO}_{2}$ from the atmosphere by the terrestrial biosphere, and growth in atmospheric $\mathrm{CO}_{2}$ in the winter, when human emissions are not balanced by natural removal mechanisms. Over Europe/Asia, there is a similar seasonal cycle, but the springtime $\mathrm{X}_{\mathrm{CO} 2}$ reductions are more rapid, as these measurements are where the terrestrial biosphere is active.

\section{The Impact of the 2015-2016 El Niño on the Carbon Cycle}

The massive 2015-2016 El Niño contributed to the anomalously large $\mathrm{X}_{\mathrm{CO} 2}$ growth rate. The OCO-2 mission started approximately 6 months before the beginning of the El Niño. The 3 ppm global increase in $\mathrm{X}_{\mathrm{CO} 2}$ recorded during this El Niño is one of the largest ever observed $(4,54)$, consistent with previous research that has shown that global $\mathrm{CO}_{2}$ increases anomalously during and in the year following large El Niño (55-59).

Diagnosis of the specific mechanisms responsible for the large $\mathrm{CO}_{2}$ growth rates (e.g. the relative importance of changes in the ocean, the humid tropics, and the semi-arid tropics), has been challenging due to a lack of observations of $\mathrm{CO}_{2}$ in those regions (60). Data from the OCO-2 mission thus provides a new window into the response of the ocean and land carbon cycle to this large-scale climate perturbation (7). Leveraging the broad coverage of OCO-2 data, Chatterjee et al. (33), Liu et al. (36), Heymann et al. (35), and Sun et al. (37) report on the quantification of $\mathrm{CO}_{2}$ emissions sources and insights into the carbon cycle response to El Niño. These studies examine the role of ocean outgassing, drought, and fire as contributors to the increased growth rate of atmospheric $\mathrm{CO}_{2}$.

Chatterjee et al. (33) used OCO-2 $\mathrm{X}_{\mathrm{CO} 2}$ observations to study the temporal evolution of $\mathrm{X}_{\mathrm{CO} 2}$ anomalies over the tropical Pacific Ocean. Using a combination of data from OCO-2, the TAO (Tropical Atmosphere Ocean) moored buoy array network (61) and MOPITT, they identify two distinct phases in the response of atmospheric $\mathrm{CO}_{2}$ - an early response driven by reduction in $\mathrm{CO}_{2}$ outgassing from the tropical Pacific Ocean followed by a lagged and much larger response driven by increased fluxes from the tropical land. To further elucidate the relationship between regional climate forcing and tropical biosphere carbon response, Liu et al. (36) contrast the 2015 carbon responses to 2011, which was a weak La Niña year with near-average temperature and precipitation over the tropical continents. They quantify net biosphere exchange (NBE, i.e., the combined effects of respiration, fire, and GPP) for 2015 and 2011, respectively, by assimilating $\mathrm{X}_{\mathrm{CO} 2}$ observations from the OCO-2 and Greenhouse gases Observing SATellite (GOSAT) into the NASA Carbon Monitoring System Flux (CMS-Flux) inversion system. To further partition the NBE into gross primary production, biomass burning, and residual respiration carbon fluxes, they optimized GPP and biomass burning fluxes with solar induced fluorescence (SIF) from GOSAT (62) and CO observations from MOPITT (63), respectively.

The impacts of El Niño on the carbon cycle are complex $(33,36)$ - temperature and rainfall changes in Southeast Asia, Africa, and South America are distinct, resulting in diverse carbon 
cycle impacts. $\mathrm{X}_{\mathrm{CO} 2}$ decreased over the tropical Pacific Ocean, but flows of carbon were larger to the tropical atmosphere over all 3 continents. Over South America, dry conditions reduced gross primary production (GPP), resulting in a net increase in the flux of carbon to the atmosphere. Over Africa, higher atmospheric temperatures drove increased respiration $\left(\mathrm{R}_{\mathrm{eco}}\right)$ but near normal GPP, increasing carbon flux to the atmosphere. Southeast Asia experienced higher temperatures and dry conditions, increased vulnerability to fire from land use, and increased emissions of $\mathrm{CO}_{2}$. See Liu et al. (36) for additional discussion.

\section{OCO-2 Measurements in Context of Other Remote Sensing Data}

OCO-2 is not the first instrument to measure $\mathrm{CO}_{2}$ from space, but its data have unique characteristics relative to existing datasets. Space-based measurements of $\mathrm{CO}_{2}$ have been made in the thermal infrared beginning in the early 2000s with the Atmospheric Infrared Sounder (64), and are now being made by several other instruments. However, extracting surface source/sink information from these measurements has been largely unsuccessful, owing to their low sensitivity to near-surface $\mathrm{CO}_{2}$, which provides the most information on surface exchange (65, 66). The SCanning Imaging Absorption SpectroMeter for Atmospheric CartograpHY (SCIAMACHY) instrument made near infrared measurements of column $\mathrm{CO}_{2}$ from 2002 to 2012 , though with relatively coarse spatial resolution $\left(30 \times 60 \mathrm{~km}^{2}\right)$ and lower sensitivity (4-8 ppm) (67-70). The Japanese GOSAT mission launched in 2009 (71, 72) was the first mission whose primary goal was to measure greenhouse gases (carbon dioxide and methane) from space. The GOSAT mission has fostered significant international scientific collaboration, leading to a deeper understanding of the utility of total column $\mathrm{CO}_{2}$ measurements from space. The GOSAT $\mathrm{CO}_{2}$ observations have formed the backbone of a number of important scientific studies. The primary limitation of the GOSAT measurement scheme is its low sounding density, with a single, $85 \mathrm{~km}^{2}$ measurement per $250 \mathrm{~km}$, resulting in fewer than 1000 cloud free soundings each day.

The $\mathrm{CO}_{2}$ seasonal cycle has also been studied with SCIAMACHY and GOSAT data (e.g., 73, 74-76). The GOSAT measurements have been used to characterize a number of relatively large disturbances to the carbon cycle, including reduced carbon uptake in 2010 due to the Eurasia heat wave (77), larger than average carbon fluxes in Tropical Asia in 2010 due to above-average temperatures (78), and anomalous carbon uptake in Australia (79). Parazoo et al. (62) used GOSAT $\mathrm{X}_{\mathrm{CO} 2}$ and SIF estimates to better understand the carbon balance of southern Amazonia. Ross et al. (80) used GOSAT data to obtain information on wildfire $\mathrm{CH}_{4}: \mathrm{CO}_{2}$ emission ratios. Buchwitz et al. (67) and references therein provide an excellent overview of the SCIAMACHY and GOSAT remote sensing datasets.

The OCO-2 measurements have a higher spatial resolution than GOSAT and SCIAMACHY, and include a larger number of measurements per day. OCO-2 was designed as a sampling mission, not a mapping mission, so it only samples a small fraction of the globe each day, While it would be desirable to have high precision measurements over the whole globe daily, current limitations in remote sensing create a trade off in sampling coverage and measurement precision $(81)$, and OCO-2 has been designed to have sparse sampling and high precision $(18,82)$. This trade allows OCO-2 to capture the data required for assessing regional fluxes of carbon dioxide across the globe $(32,82)$. Additionally, $\mathrm{OCO}-2 \mathrm{X}_{\mathrm{CO} 2}$ high precision allows the detection of small changes 
in regional concentrations (33) including the observations, from a single overpass, of gradients across cities that the measurement path happens to cross (46).

Similarly, SIF has been derived from SCIAMACHY $(41,83)$, GOME-2 (84) and GOSAT measurements $(39,84)$ as well as OCO-2. While these datasets span a longer period of time than OCO-2, the OCO-2 SIF product has a smaller footprint $\left(<3 \mathrm{~km}^{2}\right.$ for OCO-2 vs $2400 \mathrm{~km}^{2}$ for GOME-2, $1800 \mathrm{~km}^{2}$ for SCIAMACHY, and $85 \mathrm{~km}^{2}$ for GOSAT) and a higher signal to noise ratio $(44,85)$. As discussed in detail in Sun et al. (37), the OCO-2 SIF data provide higher single sounding precision then the other datasets, with reduced spatial coverage of the globe. These characteristics are valuable for improving our mechanistic understanding, as the OCO-2 data spatial resolution is well matched to ground-based measurements and the scales of heterogeneity in many ecosystems.

Looking forward, NASA's current plan calls for continued development of the space-based $\mathrm{CO}_{2}$ and SIF record with OCO-3, which will be deployed on the International Space Station (ISS) no earlier than the fall of 2018. While the OCO-2 and OCO-3 instruments are very similar (the core spectrometer used by OCO-3 was the flight spare for OCO-2), differences in the OCO-2 and ISS orbits and observing capabilities will further enhance the value of simultaneous measurements from these two sensors. In particular, from its near polar, sun-synchronous orbit, OCO-2 can sample most of the globe, but only measure of $\mathrm{X}_{\mathrm{CO} 2}$ and SIF at 1:30 PM local time. In contrast, while the moderate-inclination of the ISS orbit restricts OCO-3 coverage to $\pm 51^{\circ}$ latitude, the orbit precesses in time enabling $\mathrm{X}_{\mathrm{CO} 2}$ and SIF observations from dawn to dusk. Finally, while OCO-2 can collect targeted measurements over only one to two sites each day, OCO-3 will use its fast pointing mechanism to acquire thousands of measurements over up to one hundred $70 \mathrm{~km}$ by $70 \mathrm{~km}$ targets each day. Combining the OCO-2 and OCO-3 datasets will therefore enable carbon cycle investigations that require uniform sampling of the globe as well as sampling of the diurnal cycle or compact sources, such as megacities.

The combined OCO-2/OCO-3 climate data record will provide a valuable baseline for the GeoCarb mission, which was recently selected by the NASA Earth Ventures Program (86). GeoCarb will be NASA's first greenhouse gas sensor in geostationary orbit. If all goes as planned, GeoCarb will be ready for launch no earlier than 2021. It will deployed at $85^{\circ} \mathrm{West}$ longitude, where it can produce continuous global maps of $\mathrm{X}_{\mathrm{CO} 2}, \mathrm{X}_{\mathrm{CH} 4}$, and $\mathrm{X}_{\mathrm{CO}}$ over the North and South American continents. Internationally, a number of near infrared $\mathrm{CO}_{2}$ measurements are beginning or planned, including China's TanSat, which was launched in December 2016 (87, 88), the Japanese GOSAT-2, planned to launch in 2018 (89), and the French Space Agency's (CNES) MicroCARB, with a planned launch in 2020 (90).

The record of SIF measurements will also expand greatly in the future. Sensors that will return SIF measurement include OCO-3, TROPOMI (91), ESA FLEX (92), GOSAT-2, MicroCARB, and, GeoCARB. As with $\mathrm{CO}_{2}$, these new missions will both extend the SIF record in time, and provide new capabilities, such as sampling over a range of daylight hours and with a range of spatial resolutions.

\section{Conclusions}


The dense, global, $\mathrm{X}_{\mathrm{CO} 2}$ and SIF datasets from GOSAT and OCO-2 are being combined with data from MODIS, OMI, and MOPPIT and used to disentangle the processes driving the carbon cycle on regional scales. The accompanying reports in this collection use these data to discriminate the impacts of fossil fuel emissions, fires, and the 2015-2016 El Niño on the atmospheric $\mathrm{CO}_{2}$ budget. A longer data record is needed to document the carbon cycle's response as the tropical climate relaxes back to its background state. An even longer record will be needed to fully characterize the interactions between the present-day carbon cycle and climate system. This information is crucial for the development and validation of improved coupled carbon-climate models for predicting the carbon cycle's response to a warming climate. Fortunately, as OCO-2 completes its 2-year prime mission and begins its first extended mission, the spacecraft and instrument remain healthy and data products with improved accuracy and coverage are in development.

\section{References and Notes:}

1. P. Ciais et al., in Climate change 2013: the physical science basis. Contribution of Working Group I to the Fifth Assessment Report of the Intergovernmental Panel on Climate Change. (Cambridge University Press, 2014), pp. 465-570.

2. G. Marland, T.A. Boden, R. J. Andres, Global, Regional, and National Fossil Fuel CO Emissions. In Trends: A Compendium of Data on Global Change (Carbon Dioxide Information Analysis Center, Oak Ridge National Laboratory, U.S. Department of Energy, Oak Ridge, Tennessee, 2008)

3. C. Le Quéré et al., Global carbon budget 2015. Earth System Science Data 7, 349-396 (2015).

4. Dlugokencky, E. and P. Tans (2017). "Greenhouse Gas Reference Network Site Information." Earth System Research Laboratory, Global Monitoring Division. from https://www.esrl.noaa.gov/gmd/ccgg/ggrn.php

5. M. R. Raupach et al., The declining uptake rate of atmospheric $\mathrm{CO}_{2}$ by land and ocean sinks. Biogeosciences 11, 3453 (2014).

6. C. L. Sabine et al., The oceanic sink for anthropogenic CO2. science 305, 367-371 (2004).

7. D. Schimel, B. B. Stephens, J. B. Fisher, Effect of increasing $\mathrm{CO}_{2}$ on the terrestrial carbon cycle. Proceedings of the National Academy of Sciences 112, 436-441 (2015).

8. M. Reuter et al., Satellite-inferred European carbon sink larger than expected. Atmospheric Chemistry and Physics 14, 13739-13753 (2014).

9. F. Chevallier et al., Toward robust and consistent regional CO2 flux estimates from in situ and spaceborne measurements of atmospheric CO2. Geophysical Research Letters 41, 1065-1070 (2014).

10. J. Sarmiento et al., Trends and regional distributions of land and ocean carbon sinks. Biogeosciences 7 , 2351-2367 (2010).

11. D. S. Schimel, Terrestrial ecosystems and the carbon cycle. Global change biology 1, 77-91 (1995).

12. V. K. Arora et al., Carbon-concentration and carbon-climate feedbacks in CMIP5 Earth system models. Journal of Climate 26, 5289-5314 (2013).

13. P. Friedlingstein et al., Climate-carbon cycle feedback analysis: results from the C4MIP model intercomparison. Journal of Climate 19, 3337-3353 (2006).

14. Dlugokencky, E. and P. Tans (2017). "Trends in Atmospheric Carbon Dioxide." Earth System Research Laboratory, Global Monitoring Division. from https://www.esrl.noaa.gov/gmd/ccgg/trends/gr.html

15. C. L. Zhao, P. P. Tans, Estimating uncertainty of the WMO mole fraction scale for carbon dioxide in air. Journal of Geophysical Research: Atmospheres 111, (2006).

16. T. S. L'Ecuyer, J. H. Jiang, Touring the atmosphere aboard the A-Train. Physics Today 63, 36-41 (2010).

17. D. Crisp et al., The orbiting carbon observatory (OCO) mission. Advances in Space Research 34, 700-709 (2004). 
18. D. Crisp, C. E. Miller, P. L. DeCola, NASA Orbiting Carbon Observatory: measuring the column averaged carbon dioxide mole fraction from space. Journal of Applied Remote Sensing 2, 023508-023508-023514 (2008).

19. D. Crisp et al., The on-orbit performance of the Orbiting Carbon Observatory-2 (OCO-2) instrument and its radiometrically calibrated products. Atmospheric Measurement Techniques 10, 59-81 (2017).

20. H. Bösch et al., Space-based near-infrared CO2 measurements: Testing the Orbiting Carbon Observatory retrieval algorithm and validation concept using SCIAMACHY observations over Park Falls, Wisconsin. Journal of Geophysical Research: Atmospheres 111, (2006).

21. C. O'Dell et al., The $\mathrm{ACOS} \mathrm{CO}_{2}$ retrieval algorithm-Part 1: Description and validation against synthetic observations. Atmos. Meas. Tech., 5, 99-121, doi:10.5194/amt-5-99-2012, (2012).

22. B. J. Connor et al., Orbiting Carbon Observatory: Inverse method and prospective error analysis. Journal of Geophysical Research: Atmospheres 113, (2008).

23. H. Boesch, D. Baker, B. Connor, D. Crisp, C. Miller, Global characterization of CO2 column retrievals from shortwave-infrared satellite observations of the Orbiting Carbon Observatory-2 mission. Remote Sensing 3, 270-304 (2011).

24. A. Eldering et al., The Orbiting Carbon Observatory-2: first 18 months of science data products. Atmospheric Measurement Techniques 10, 549-563, doi:10.5194/amt-10-549-2017 (2017).

25. T. E. Taylor et al., Orbiting Carbon Observatory-2 (OCO-2) cloud screening algorithms: validation against collocated MODIS and CALIOP data. Atmospheric Measurement Techniques 9, 973 (2016).

26. L. Mandrake et al., "Lite Files, Warn Levels, and Bias Correction Determination, Version 1," JPL Technical Report (NASA Jet Propulsion Laboratory, California Institute of Technology, 2015).

27. D. Wunch et al., A method for evaluating bias in global measurements of $\mathrm{CO}_{2}$ total columns from space. Atmospheric Chemistry and Physics 11, 12317-12337 (2011).

28. D. Wunch et al., The total carbon column observing network. Philosophical Transactions of the Royal Society of London A: Mathematical, Physical and Engineering Sciences 369, 2087-2112 (2011).

29. D. Wunch et al., The Total Carbon Column Observing Network's GGG2014 Data Version. Carbon Dioxide Information Analysis Center, Oak Ridge National Laboratory, Oak Ridge, Tennessee, USA, available at: doi 10, (2015).

30. D. Wunch et al., Comparisons of the Orbiting Carbon Observatory-2 (OCO-2) $\mathrm{X}_{\mathrm{CO} 2}$ measurements with TCCON. Atmos. Meas. Tech., 10, 2209-2238, https://doi.org/10.5194/amt-10-2209-2017, (2017).

31. P. Ciais et al., Europe-wide reduction in primary productivity caused by the heat and drought in 2003. Nature 437, 529-533 (2005).

32. F. Chevallier, F. M. Bréon, P. J. Rayner, Contribution of the Orbiting Carbon Observatory to the estimation of CO2 sources and sinks: Theoretical study in a variational data assimilation framework. Journal of Geophysical Research: Atmospheres 112, (2007).

33. A. Chatterjee et al., Influence of El Niño on atmospheric $\mathrm{CO}_{2}$ over the tropical Pacific Ocean: findings from NASA's OCO-2 mission. Science, (in review).

34. J. Hakkarainen, I. Ialongo, J. Tamminen, Direct space-based observations of anthropogenic $\mathrm{CO}_{2}$ emission areas from OCO-2. Geophysical Research Letters 43, (2016).

35. J. Heymann et al., $\mathrm{CO}_{2}$ emission of Indonesian fires in 2015 estimated from satellite-derived atmospheric $\mathrm{CO}_{2}$ concentrations. Geophysical Research Letters 44, 1537-1544 (2017).

36. J. Liu et al., Contrasting carbon cycle responses of the tropical continents to the 2015 E1 Niño. Science, (in review).

37. Y. Sun et al., OCO-2 advances photosynthesis observation from space via solar-induced chlorophyll fluorescence. Science, (in review).

38. C. Frankenberg, A. Butz, G. Toon, Disentangling chlorophyll fluorescence from atmospheric scattering effects in $\mathrm{O} 2$ A-band spectra of reflected sun-light. Geophysical Research Letters 38, (2011).

39. C. Frankenberg et al., New global observations of the terrestrial carbon cycle from GOSAT: Patterns of plant fluorescence with gross primary productivity. Geophysical Research Letters 38, (2011).

40. J. Joiner, Y. Yoshida, A. Vasilkov, E. Middleton, First observations of global and seasonal terrestrial chlorophyll fluorescence from space. Biogeosciences 8, 637-651 (2011).

41. J. Joiner et al., Filling-in of near-infrared solar lines by terrestrial fluorescence and other geophysical effects: simulations and space-based observations from SCIAMACHY and GOSAT. Atmospheric Measurement Techniques 5, 809 (2012).

42. L. Guanter et al., Retrieval and global assessment of terrestrial chlorophyll fluorescence from GOSAT space measurements. Remote Sensing of Environment 121, 236-251 (2012). 
43. C. Frankenberg, C. O'Dell, L. Guanter, J. McDuffie, Remote sensing of near-infrared chlorophyll fluorescence from space in scattering atmospheres: implications for its retrieval and interferences with atmospheric $\mathrm{CO}_{2}$ retrievals. Atmospheric Measurement Techniques 5, 2081-2094 (2012).

44. C. Frankenberg et al., Prospects for chlorophyll fluorescence remote sensing from the Orbiting Carbon Observatory-2. Remote Sensing of Environment 147, 1-12 (2014).

45. L. E. Ott et al., Assessing the magnitude of $\mathrm{CO}_{2}$ flux uncertainty in atmospheric $\mathrm{CO}_{2}$ records using products from NASA's Carbon Monitoring Flux Pilot Project. Journal of Geophysical Research: Atmospheres 120, 734-765 (2015).

46. F. M. Schwandner et al., Space-Borne Detection of Carbon Dioxide Localized Sources. Science, (in review).

47. T. Oda, S. Maksyutov, A very high-resolution $(1 \mathrm{~km} \times 1 \mathrm{~km})$ global fossil fuel $\mathrm{CO}_{2}$ emission inventory derived using a point source database and satellite observations of nighttime lights. Atmospheric Chemistry and Physics 11, 543-556 (2011).

48. G. R. Van der Werf et al., Global fire emissions and the contribution of deforestation, savanna, forest, agricultural, and peat fires (1997-2009). Atmospheric Chemistry and Physics 10, 11707-11735 (2010).

49. L. Giglio, J. T. Randerson, G. R. Werf, Analysis of daily, monthly, and annual burned area using the fourth-generation global fire emissions database (GFED4). Journal of Geophysical Research: Biogeosciences 118, 317-328 (2013).

50. T. T. Van Leeuwen et al., Biomass burning fuel consumption rates: a field measurement database. Biogeosciences 11, 7305-7329 (2014).

51. S. Akagi et al., Emission factors for open and domestic biomass burning for use in atmospheric models. Atmospheric Chemistry and Physics 11, 4039-4072 (2011).

52. V. Huijnen et al., Fire carbon emissions over maritime southeast Asia in 2015 largest since 1997. Scientific reports 6, 26886 (2016).

53. G. Roberts, M. Wooster, E. Lagoudakis, Annual and diurnal African biomass burning temporal dynamics. Biogeosciences Discussions 5, 3623 (2008).

54. Q. Wang et al., in Remote Sensing of the Environment: 19th National Symposium on Remote Sensing of China. (International Society for Optics and Photonics, 2015), pp. 96690T-96690T-96696.

55. R. Bacastow, Modulation of atmospheric carbon dioxide by the Southern Oscillation. Nature 261, 116-118 (1976).

56. R. Bacastow et al., Atmospheric carbon dioxide, the Southern Oscillation, and the weak 1975 El Niño. Science 210, 66-68 (1980).

57. C. Keeling, R. Revelle, Effects of El Nino/Southern Oscillation on the atmospheric content of carbon dioxide. Meteoritics 20, 437-450 (1985).

58. C. D. Keeling, T. P. Whorf, M. Wahlen, J. van der Plicht, Interannual extremes in the rate of rise of atmospheric carbon dioxide since 1980. Nature 375, 666 (1995).

59. M. L. Thompson, I. Enting, G. Pearman, P. Hyson, Interannual variation of atmospheric $\mathrm{CO}_{2}$ concentration. Journal of Atmospheric Chemistry 4, 125-155 (1986).

60. J. L. Sarmiento, N. Gruber, in Ocean biogeochemical dynamics. (Princeton University Press, Princeton, New Jersey, 2006), pp. 392-453.

61. M. J. McPhaden, A. J. Busalacchi, D. L. Anderson, A TOGA retrospective. Oceanography 23, 86-103 (2010).

62. N. C. Parazoo et al., Terrestrial gross primary production inferred from satellite fluorescence and vegetation models. Global change biology 20,3103-3121 (2014).

63. Z. Jiang et al., Impact of model errors in convective transport on CO source estimates inferred from MOPITT CO retrievals. Journal of Geophysical Research: Atmospheres 118, 2073-2083 (2013).

64. M. Chahine et al., Satellite remote sounding of mid-tropospheric CO2. Geophysical Research Letters 35, (2008).

65. F. Chevallier et al., AIRS-based versus flask-based estimation of carbon surface fluxes. Journal of Geophysical Research: Atmospheres 114, (2009).

66. F.-M. Bréon, P. Ciais, Spaceborne remote sensing of greenhouse gas concentrations. Comptes Rendus Geoscience 342, 412-424 (2010).

67. M. Buchwitz et al., Global satellite observations of column-averaged carbon dioxide and methane: The GHG-CCI $\mathrm{XCO}_{2}$ and $\mathrm{XCH}_{4} \mathrm{CRDP} 3$ data set. Remote Sensing of Environment, (2017). 
68. M. Reuter et al., Retrieval of atmospheric $\mathrm{CO}_{2}$ with enhanced accuracy and precision from SCIAMACHY: Validation with FTS measurements and comparison with model results. Journal of Geophysical Research: Atmospheres 116, (2011).

69. M. Reuter et al., A method for improved SCIAMACHY $\mathrm{CO}_{2}$ retrieval in the presence of optically thin clouds. Atmospheric Measurement Techniques 3, 209-232 (2010).

70. O. Schneising et al., Long-term analysis of carbon dioxide and methane column-averaged mole fractions retrieved from SCIAMACHY. Atmospheric Chemistry and Physics 11, 2863-2880 (2011).

71. A. Kuze, H. Suto, M. Nakajima, T. Hamazaki, Thermal and near infrared sensor for carbon observation Fourier-transform spectrometer on the Greenhouse Gases Observing Satellite for greenhouse gases monitoring. Applied optics 48, 6716-6733 (2009).

72. T. Yokota et al., Global concentrations of $\mathrm{CO}_{2}$ and $\mathrm{CH}_{4}$ retrieved from GOSAT: First preliminary results. Sola 5, 160-163 (2009).

73. M. Buchwitz et al., The Greenhouse Gas Climate Change Initiative (GHG-CCI): Comparison and quality assessment of near-surface-sensitive satellite-derived $\mathrm{CO}_{2}$ and $\mathrm{CH}_{4}$ global data sets. Remote Sensing of Environment 162, 344-362 (2015).

74. M. Reuter et al., A joint effort to deliver satellite retrieved atmospheric $\mathrm{CO}_{2}$ concentrations for surface flux inversions: the ensemble median algorithm EMMA. Atmospheric Chemistry and Physics 13, 1771-1780 (2013).

75. H. Lindqvist et al., Does GOSAT capture the true seasonal cycle of carbon dioxide? Atmos. Chem. Phys 15, 13023-13040 (2015).

76. D. Wunch et al., The covariation of Northern Hemisphere summertime CO 2 with surface temperature in boreal regions. Atmospheric Chemistry and Physics 13, 9447-9459 (2013).

77. S. Guerlet et al., Reduced carbon uptake during the 2010 Northern Hemisphere summer from GOSAT. Geophysical Research Letters 40, 2378-2383 (2013).

78. S. Basu et al., The seasonal variation of the CO2 flux over Tropical Asia estimated from GOSAT, CONTRAIL, and IASI. Geophysical Research Letters 41, 1809-1815 (2014).

79. R. Detmers et al., Anomalous carbon uptake in Australia as seen by GOSAT. Geophysical Research Letters 42, 8177-8184 (2015).

80. A. N. Ross, M. J. Wooster, H. Bösch, R. Parker, First satellite measurements of carbon dioxide and methane emission ratios in wildfire plumes. Geophysical Research Letters 40, 4098-4102 (2013).

81. W. J. Larson, J. R. Wertz, "Space mission analysis and design," (Microcosm, Inc., Torrance, CA (US), 1992).

82. C. Miller et al., Precision requirements for space-based data. Journal of Geophysical Research: Atmospheres 112, (2007).

83. J. Joiner, Y. Yoshida, L. Guanter, E. M. Middleton, New methods for the retrieval of chlorophyll red fluorescence from hyperspectral satellite instruments: simulations and application to GOME-2 and SCIAMACHY. Atmospheric Measurement Techniques Discussions 9, 3939-3967 (2016).

84. J. Joiner et al., The seasonal cycle of satellite chlorophyll fluorescence observations and its relationship to vegetation phenology and ecosystem atmosphere carbon exchange. Remote Sensing of Environment 152, 375-391 (2014).

85. C. Frankenberg et al., The Orbiting Carbon Observatory (OCO-2): spectrometer performance evaluation using pre-launch direct sun measurements. Atmospheric Measurement Techniques 8, (2015).

86. J. J. B. Kumer et al., in SPIE Optical Engineering + Applications. (International Society for Optics and Photonics, 2013), pp. 88670K-88670K-88616.

87. Y. Liu et al., in AGU Fall Meeting Abstracts. (2012), vol. 1, pp. 01.

88. D. Liu et al., The retrieval algorithm for a satellite-borne $\mathrm{CO}_{2}$-sounder: Preliminary results in near infrared band. Optik-International Journal for Light and Electron Optics 127, 8613-8620 (2016).

89. M. Nakajima, A. Kuze, H. Suto, in SPIE 8533, Sensors, Systems, and Next-Generation Satellites XVI. (International Society for Optics and Photonics, 2012), pp. 853306-853306-853310.

90. C. Buil et al., in SPIE Remote Sensing. (International Society for Optics and Photonics, 2011), pp. 817621817621-817611.

91. L. Guanter et al., Potential of the TROPOspheric Monitoring Instrument (TROPOMI) onboard the Sentinel-5 Precursor for the monitoring of terrestrial chlorophyll fluorescence. Atmospheric Measurement Techniques 8, 1337-1352 (2015).

92. S. Cogliati et al., Retrieval of sun-induced fluorescence using advanced spectral fitting methods. Remote Sensing of Environment 169, 344-357 (2015). 
Acknowledgments: Retrieved Level 2 OCO-2 XCO2 (version v7r) data used in this study are archived in permanent repository at NASA's Goddard Space Flight Center's Earth Sciences Data and Information Services Center (GES-DISC), and are also available at NASA's Jet Propulsion Laboratory (http://co2.jpl.nasa.gov). Part of the research described in this paper was carried out at the Jet Propulsion Laboratory, California Institute of Technology, under a contract with the National Aeronautics and Space Administration. The animation was created provided by B. Weir, L. Ott, S. Pawson, H. Mitchell, and G. Shirah at Goddard Space Flight Center and the Scientific Visualization Studio. BW, LO, and SP were supported by the NASA Carbon Monitoring System and the OCO-2 Science Team NASA ROSES projects. K. Yuen assisted with figure production. JH and JT were supported by the Academy of Finland INQUIRE (grant number 267442) and CARB-ARC (grant number 285630) projects.

Copyright 2017, California Institute of Technology. Government sponsorship acknowledged. 

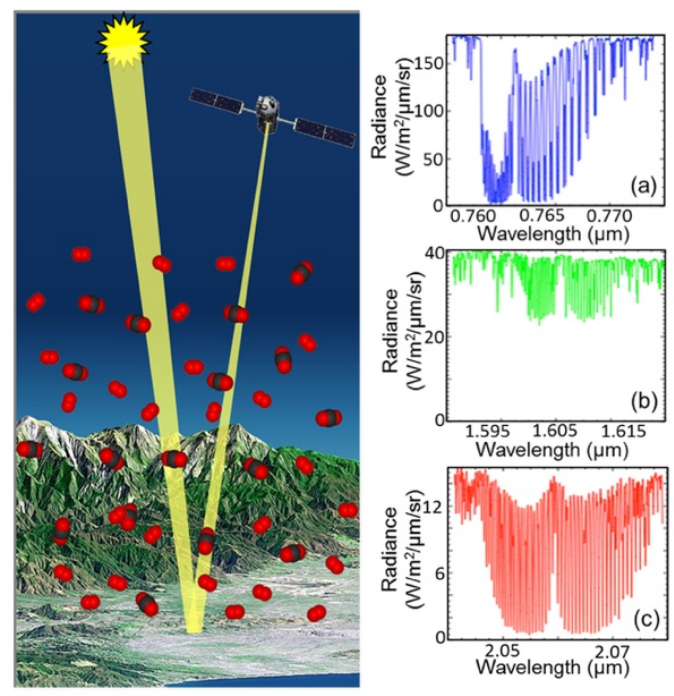

Fig. 1. OCO-2 detects sunlight that has traveled through the atmosphere and is reflected back to space. The sunlight is partially absorbed by the $\mathrm{O}_{2} \mathrm{~A}$-band (a) and the weak and strong $\mathrm{CO}_{2}$ bands centered near 1.61 (b) and $2.06 \mu \mathrm{m}$ (c). 

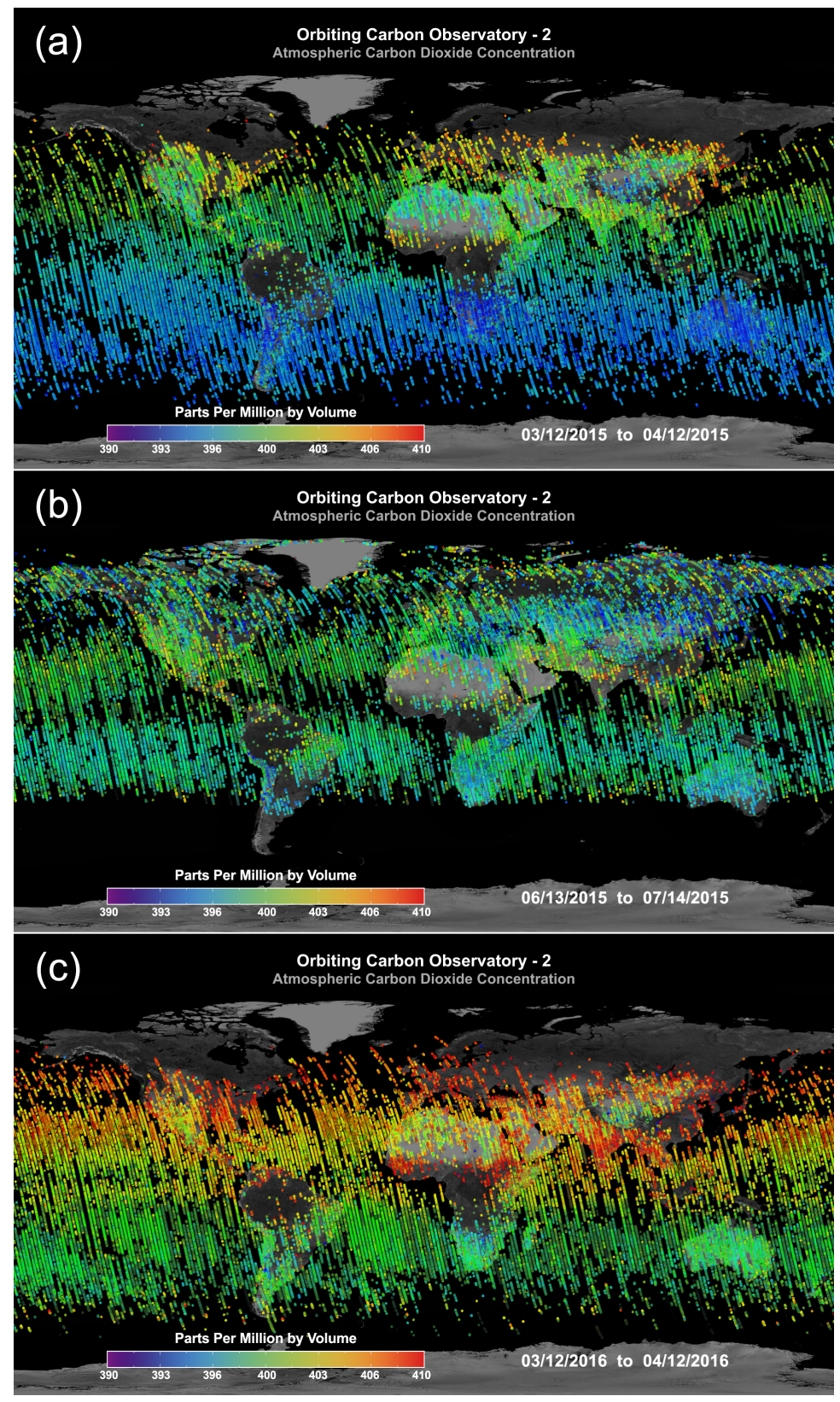

Fig. 2. Maps of OCO-2 $\mathrm{X}_{\mathrm{CO} 2}$ (bias corrected with quality flags applied) over 32 day periods in (a) March/April 2015, (b) June/July 2015, and (c) March/April 2016. The measurement area of each sounding has been exaggerated for visibility on a global scale. 


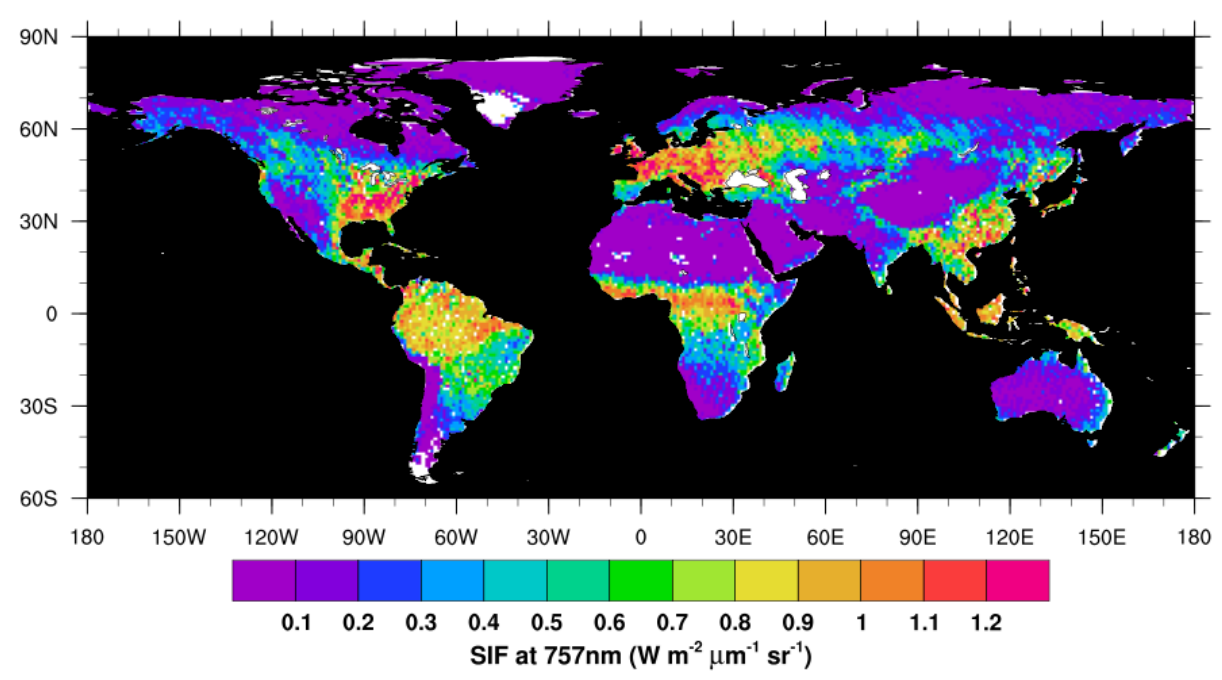

Fig. 3 The OCO-2 SIF retrieval at $757 \mathrm{~nm}$ on $1^{\circ}$ by $1^{\circ}$ grid for the spring (i.e., the mean of AprilMay-June for 2015 and 2016).

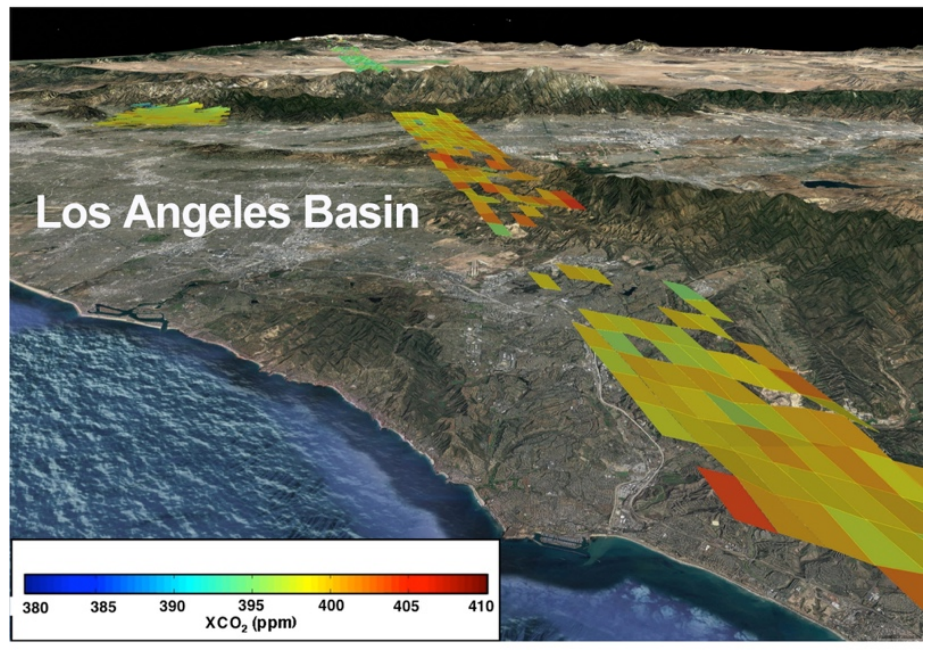

Fig. 4. OCO-2 $\mathrm{X}_{\mathrm{CO} 2}$ measurements across the Los Angeles basin and into the desert in north of Los Angeles taken during one overpass on Spetember $8^{\text {th }}, 2015$. The measurement swath is 10 $\mathrm{km}$ across. Two special set of measurements taken for validation purposes, one at Caltech, and one at Armstrong Flight Research Center are also displayed. 


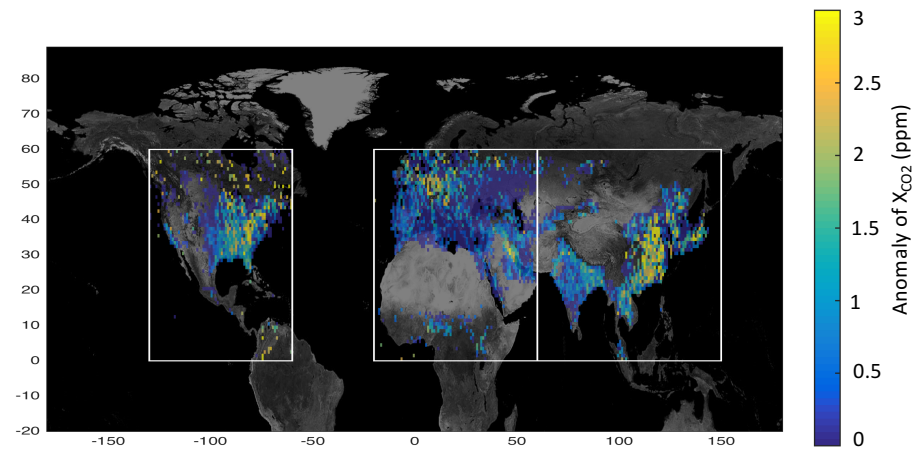

Fig. 5. Maps of the OCO-2 $\mathrm{X}_{\mathrm{CO} 2}$ anomaly (mean in each grid box of the daily anomaly from the regional median) in 1 degree by 1 degree cells between September 2014 and April 2016. The anomalies are only plotted for the regions identified as clusters of enhancements due to fossil fuel burning in Hakkarainen et al. (2016).
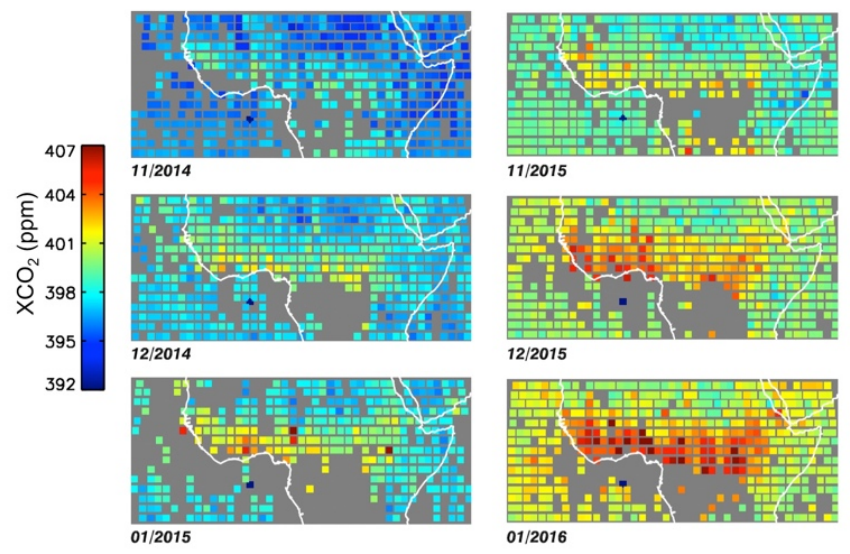

Fig. 6. Maps of OCO-2 $\mathrm{X}_{\mathrm{CO} 2}$ over sub-Saharan Africa for the beginning of the biomass burning seasons of 2015 and 2016, showing the rapid regional increase in $\mathrm{X}_{\mathrm{CO} 2}$. The data have been averaged to 2 degree by 2 degree bins each month, after bias correction and quality screening were applied. 


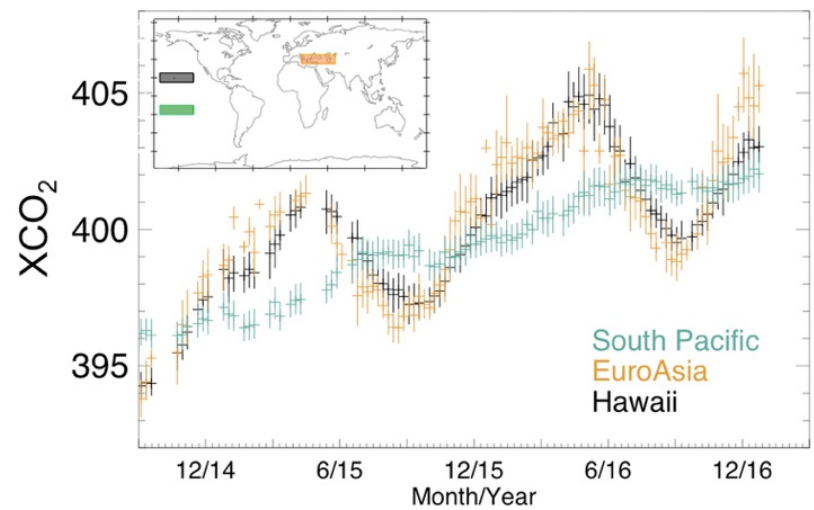

Fig. 7. Timeseries of weekly OCO-2 $\mathrm{X}_{\mathrm{CO} 2}$ averages for regions around Hawaii, the Southern Pacific Ocean, and EuroAsia, showing the contrast of the seasonal cycle in the Northern and Southern Hemisphere that is clearly observed by OCO-2. The data have bias correction and quality screening applied.

Animation 1: Results of the assimilation of OCO-2 $\mathrm{X}_{\mathrm{CO} 2}$ data into a high-resolution global model for March 2015 through July 2015, highlighting the springtime reduction in atmospheric $\mathrm{CO}_{2}$. 